\title{
Сучасні методи комплексного та персоніфікованого лікування раку шлунка (огляд літератури)
}

\author{
Запорізький держсавний медичний університет \\ Одержано 19.12.2019 \\ Прийнято до друку 28.01.2020 \\ DOI:10.32471/clinicaloncology.2663-466X.36-4.26773
}

\begin{abstract}
На сьогодні рак шлунка є однією з найбільш актуальних проблем сучасної онкології. Згідно з даними Національного канцерреєстру, за показниками захворюваності та смертності рак шлунка посідає 4-те місце $(7,1 \%)$ серед чоловіків та 8-ме місце $(4,2 \%)$ - серед жінок. За даними літератури, загальна 5-річна виживаність при резектабельному раку шлунка становить близько 53,5\%, саме тому проблема правильного вибору тактики лікування $\epsilon$ надзвичайно актуальною. Згідно 3 міжнародними рекомендаціями у якості терапії для хворих на резектабельний рак шлунка IB-III стадії застосовуються кілька варіантів комплексного лікування: неоад'ювантна хіміотерапія або неоад'ювантна хіміопроменева терапія з подальшим хірургічним лікуванням; ад'ювантна хіміотерапія або ад'ювантна хіміопроменева терапія після хірургічного втручання; передопераційна хіміотерапія, що складається з неоад'ювантної та ад'ювантної хіміотерапії. У цій статті проаналізовано результати клінічних досліджень, основною метою яких було встановити найбільш ефективний підхід до лікування раку шлунка IB-III стадії шляхом поєднання різних методів терапії. Мета роботи: огляд спеціалізованої наукової літератури для виявлення найбільш ефективного підходу для лікування хворих на рак шлунка IB-III стадії.
\end{abstract}

Ключові слова: рак шлунка, клінічне дослідження, комплексне лікування, хірургічне лікування, хіміотерапія, хіміопроменеве лікування, виживаність.

На сьогодні рак шлунка (РШ) є однією з найбільш актуальних проблем сучасної онкології, оскільки захворюваність та смертність пацієнтів від цієї патології залишаються високими. Згідно з даними Національного канцер-реєстру, в Україні у 2018 р. захворюваність на РШ становила 19,3 випадку на 100 тис. населення $(25,0$ - чоловіки та 14,4 - жінки); показник смертності становив 14,8 (19,6 і 10,6 відповідно), що є значно вищим за загальноєвропейський рівень (13,7 та 10,4 відповідно). У $31,2 \%$ хворих РШ було діагностовано на I-II стадіях, у 22,3\% пацієнтів - на III стадії [1]. За прогнозами, у 2020 р. у світі буде зареєстровано до 870 тис. нових випадків захворювання на РШ, а показник смертності становитиме 10,4 на 100 тис. населення, що є другим показником смертності після раку легені $(17,8)$ [2]. Нині єдиним методом лікування, шо дає шанс на повне одужання, $є$ хірургічний. Однак згідно з даними міжнародних рекомендацій, лікування резектабельного РШ IB-III стадії є комплексним (операція у поєднанні з ад'ювантною або неоад'ювантною хіміопроменевою терапією (НАХПТ), оскільки саме такий підхід показує кращі результати лікування у порівнянні з лише хірургічним втручанням [2, 3]. Проте на сьогодні немає чіткого консенсусу щодо вибору оптимальної тактики комплексного лікування цієї когорти пацієнтів, що робить питання вибору терапії резектабельного РШ дійсно актуальним.

На сьогодні ефективність неоад'ювантної хіміотерапії (НАХТ) доведена в багатьох дослідженнях [4-7]. Так, згідно з даними багатоцентрових клінічних досліджень 3-ї фази FNCLCC та FFCD було виявлено, що у групі хворих із застосуванням НАХТ, що отримували передопераційну хіміотерапію за схемою цисплатин +5 -флуороурацил, спостерігалися значно кращі показники безрецидивної та загальної 5-річної виживаності, ніж у групі лише хірургічного лікування (34 проти 19\%; $p=0,003$ та 38 проти 24\%; $p=0,02$ відповідно) [4].

Протилежні результати були отримано в роботі C. Schuhmacher та співавторів [5]. У клінічне дослідження були включені 144 пацієнти з РШ ІВ-III стадії. Хворі у неоад’ювантному режимі отримали 2 цикли терапії за схемою цисплатин + лейковорин + 5-флуороурацил. У групі НАХТ медіана загальної виживаності становила 64,62 проти 52,53 міс у групі тільки хірургічного лікування, однак різниця виявилася статистично незначущою $(\mathrm{p}=0,466)$.
У ряді досліджень показано позитивний клінічний ефект від комбінації НАХТ та променевої терапії. Так, у дослідженні РОЕТ брали участь хворі на рак дистального відділу стравоходу або кардіального відділу шлунка IIA-III стадії [6]. Усі пацієнти були розділені на 2 групи: 1-ша група отримувала комбінацію НАХТ + операція, 2-га група - НАХПТ + операція. При додаванні променевої терапії спостерігалося статистично значуще покращення загальної виживаності пацієнтів. Так, у групі НАХПТ загальна 3- та 5-річна виживаність становила 46,7 та 39,5\% відповідно, водночас у групі НАХТ цей показник становив 26,1 та $24,4 \%$ відповідно $(\mathrm{p}=0,05)$.

Аналогічні результати отримані в дослідженні групи CROSS, у яке були також включені пацієнти з раком нижньої третини стравоходу або стравохідно-шлункового переходу [7]. Результати аналізу показали, що у групі НАХПТ медіана загальної виживаності становила 49,4 проти 24,0 міс у групі пацієнтів, що отримували тільки хірургічне лікування $(\mathrm{p}=0,003)$. Варто відмітити, що перевага НАХПТ порівняно лише з хірургічним лікуванням спостерігалася на всіх етапах дослідження. Так 3- та 5 річна виживаність у групі НАХПТ становила 58 та $47 \%$ відповідно порівняно з 44 та $34 \%$ в групі лише хірургічного лікування. Медіана безрецидивної виживаності у пацієнтів, у яких застосовували НАХПТ, не була досягнута, у той час як у групі лише хірургічного лікування цей показник становив 24,2 міс $(\mathrm{p}<0,001)$.

Попри ефективність НАХТ та НАХПТ, ад'ювантна хіміотерапія (АХТ) та ад'ювантна хіміопроменева терапія (АХПТ) продовжують займати одне з провідних місць у сучасному комплексному лікуванні резектабельного РШ. Крім того, згідно з рекомендаціями Національної загальної онкологічної мережі (National Comprehensive Cancer Network - NCCN) та Японської асоціації з вивчення РШ (Japanese Gastric Cancer Association - JGCA), хворим на РШ IB-III стадії рекомендоване проведення АХТ або АХПТ [2, 8]. Такий висновок було зроблено також і на основі результатів дослідження NCT00152217 [9]. Клінічним дослідженням було охоплено 1059 хворих на РШ IB-III стадії. Пацієнти були розподілені на 2 групи: 1-ша група отримувала АХТ на основі препарату S1 (пероральний фторпіримідин), 2-й групі проводилося лише хірургічне лікування. У групі АХТ 3-річна безрецидивна вижи- 
ваність становила 72,2\% порівняно з групою тільки хірургічного лікування - 59,6\% (p<0,001). Аналіз загальної 3- та 5-річної виживаності продемонстрував виражений клінічний ефект у когорті пацієнтів із застосуванням АХT 80,1 та 71,7\% відповідно проти 70,1 та $61,1 \%(\mathrm{p}=0,003)$ відповідно у групі лише хірургічного лікування.

Незважаючи на доведену ефективність АХТ, незрозумілим $€$ питання вибору найбільш оптимальної схеми для іiї проведення. Згідно з даними метааналізу 17 досліджень групою GASTRIC було доведено, що під час AXT на основі 5-флуороурацилу відмічалося статистично значуще покращення безрецидивної $(\mathrm{p}<0,001)$ та загальної виживаності $(\mathrm{p}<0,001)$ [10].

У роботі Е. Вајеtta та співавторів опубліковано результати аналізу дослідження NCT01640782, у якому порівнювалися різні схеми АХT [11]. 1-ша група пацієнтів отримувала лікування за схемою FOLFIRI з подальшим призначенням комбінації доцетаксел + цисплатин, у 2-й групі проводилося лікування комбінацією 5-флуороурацил + лейковорин. 5-річна безрецидивна виживаність становила 44,6\% в обох групах $(\mathrm{p}=0,974)$, загальна виживаність $-51,0$ та 50,6\% відповідно $(\mathrm{p}=0,865)$. Таким чином, інтенсифікація лікування не продемонструвала клінічної переваги у строках загальної та безрецидивної виживаності.

Схожі результати отримано у роботі Y. Kang та співавторів [12]. У дослідженні схема мітоміцин-С + доксифлуридин + цисплатин не показала переваги над комбінацією мітоміцин-С + доксифлуридин. За результатами аналізу, між двома групами не виявлено статистично значущої різниці у показниках безрецидивної виживаності (5-річна виживаність без прогресування $-61,1 \%$ у групі застосування мітоміцину-C + доксифлуридину та $57,9 \%$ - у групі прийому мітоміцину-С + доксифлуридину + цисплатину; $\mathrm{p}=0,39)$ та загальної виживаності (5-річна загальна виживаність $-66,5 \%$ у групі прийому мітоміцину-С + доксифлуридину та $65,0 \%-$ у групі застосування мітоміцину-С + доксифлуридину + цисплатину; $\mathrm{p}=0,33)$.

У дослідженні S. Yamada та співавторів при додаванні цисплатину до схеми 5-флуороурацил + лейковорин у режимі AXT не спостерігалося покращення показників виживаності пацієнтів [13]. Так, медіана загальної виживаності в групі 3 використанням цисплатину становила 52 міс, у контрольній групі -53 міс $(\mathrm{p}=0,325)$. Показники загальної 3-річної виживаності у групі 5-флуороурацилу становив $84,46 \%$, а у когорті із застосуванням 5-флуороурацилу/цисплатину $-75,04 \%$, однак різниця у показниках виявилася статистично незначущою.

У ряді досліджень показано клінічний ефект від комбінації AXT з променевою терапією. Так, у дослідженні А. Јасоте та співавторів порівнювали ефективність АХПТ з лише хірургічним лікуванням [14]. У групі АХПТ загальна 3-річна виживаність становила 64,4 проти $61,7 \%$ у групі лише хірургічного лікування $(\mathrm{p}=0,415)$. Однак під час мультиваріантного аналізу було виявлено, шо під час проведення АХПТ знижувався ризик смерті від РШ на 54\% (коефіцієнт небезпеки 0,46; $95 \%$ довірчий інтервал (ДІ) 0,26-0,82, p=0,008).

У схожому дослідженні S. Smalley та співавторів було виявлено стійкий позитивний клінічний ефект від проведення АХПТ [15]. У когорті пацієнтів із застосуванням АХПТ медіана загальної виживаності становила 35 міс, у той час як у групі лише хірургічного лікування -27 міс $(\mathrm{p}=0,0046)$; медіана безрецидивної виживаності становила 27 та 19 міс відповідно $(\mathrm{p}<0,001)$.

Однак у роботі W. Costa та співавторів під час проведення АХПТ загальна 5-річна виживаність становила 70,9\%, тоді як у групі хірургічного лікування - лише $54,1 \%$, проте різниця у показниках виявилася статистично незначущою $(\mathrm{p}=0,173)$, безрецидивна виживаність $-59,1$ та 53,5\% відповідно $(\mathrm{p}=0,423)[16]$

На сьогодні немає консенсусу щодо переваги АХПТ над AXT. Так, у дослідженні ARTIST лікування проведено 458 хво- рим зі злоякісним захворюванням шлунка IB-III стадії [17]. При аналізі 5-річної виживаності пацієнтів не відмічено переваги АХПТ порівняно з АХТ (75 проти 73\%) (

Аналогічні результати були отримані в роботі T. Sevim та співавторів (2015) [18]. Аналіз характеру рецидивування процесу виявив, що в обох групах пацієнтів не спостерігалося різниці в частоті виникнення місцевого рецидиву $(14,3 \%$ у групі АХТ проти $15,7 \%$ у групі АХПТ, $\mathrm{p}=0,89)$, перитонеального поширення хвороби $(29,4$ проти $23,5 \%, \mathrm{p}=0,62)$ та появі віддалених метастазів $(57,1$ проти $45,1 \%, \mathrm{p}=0,42)$. Медіана загальної виживаності у групі АХТ становила 29 міс, а для групи АПХТ - 32 міс. Також у дослідженні не виявлено різниці у загальній 5-річній та безрецидивній виживаності між групами AХТ та АХПТ (23,8 проти $34,4 \%, p=0,74$; та 24,1 проти $32,9 \%$, $\mathrm{p}=0,80$ відповідно).

У цілому ряді досліджень показана клінічна ефективність як НАХТ, так АХТ, однак залишається незрозумілим, який підхід забезпечує кращі результати лікування пацієнтів із резектабельним РШ. N. Fazio та співавтори в 2016 р. опублікували результати 10-річного спостереження після клінічного дослідження SAKK 43/99 [19]. У роботі порівнювали віддалені результати лікування пацієнтів з проведеною НАХТ та АХT. У дослідженні хіміотерапія проводилася за схемою DCF (доцетаксел, цисплатин, 5-флуороурацил) в обох групах хворих. За отриманими результатами медіана загальної виживаності становила 4,3 року в групі НАХТ та 3,7 року у групі АХТ $(\mathrm{p}=0,5)$. Загальна 5-річна виживаність в групі НАХТ становила $47 \%$, у групі АХТ - 46\%, 10-річна - 44 та $36 \%$ відповідно $(\mathrm{p}=0,5)$. Медіана безрецидивної виживаності не відрізнялася в обох групах і становила 2,5 року. Також не відмічено переваги у НАХТ порівняно з АХТ при оцінці 5-річної безрецидивної виживаності. Проте у ході подальшого аналізу було виявлено різницю в показниках 10-річної безрецидивної виживаності$44,1 \%$ у групі НАХТ проти $29,4 \%$ у групі АХТ, однак ці дані виявилися статистично незначущими $(\mathrm{p}=0,4)$.

У 2014 p. Z. Sun з колегами у схожому дослідженні виявили, що проведення HAXT за схемою FOLFOX 4 (лейковорин, 5-флуороурацил, оксаліплатин) значно підвищує показники виживаності пацієнтів із РШ на ранніх стадіях [20]. Так, у групі НАХТ загальна 3-річна виживаність становила 73,9\%, у групі AXТ $-40 \%$, медіана загальної виживаності - 29 та 22 міс відповідно ( $\mathrm{p}=0,013)$. 3-річна безрецидивна виживаність становила $60,9 \%$ у групі неоад'ювантного лікування проти $34,3 \%$ у групі ад'ювантної терапії, медіана 3-річної безрецидивної виживаності становила 26 проти 18 міс відповідно $(\mathrm{p}=0,019)$.

На тепер усе більшого розповсюдження набуває періоперативна хіміотерапія як опція лікування пацієнтів з операбельним РШ. Такий інтерес базується на результатах кількох рандомізованих досліджень, у яких показана беззаперечна перевага такого підходу серед інших варіантів лікування. Так, у клінічному дослідженні CRITICS (NCT00407186) лікування отримували 788 пацієнтів з РШ [21]. Хворим у групі періоперативної хіміотерапії проводилося лікування за схемою епірубіцин + препарати платини + капецитабін. Пацієнтам контрольної групи проводилася АХПТ (променева терапія + цисплатин/капецитабін). За результатами аналізу загальна 5-річна виживаність становила $40 \%$ у групі АХТ та $50 \%-$ у групі періоперативного лікування $(\mathrm{p}=0,05)$.

Вражаючі результати отримано у дослідженні Z.Y. Li та співавторів, у якому лікування проводилося у пацієнтів з локально розповсюдженим РШ за схемою FOLFOX [22]. У групі передопераційного лікування відмічалося статистично значуще покращення загальної 4-річної виживаності (78 проти 51\% у групі AXT) $(\mathrm{p}=0,031)$.

S. Kim та співавтори опублікували результати лікування 458 хворих на РШ та рак нижньої третини стравоходу IA-III стадії [23]. Дослідники ставили за мету визначення найбільш оптимального режиму передопераційної хіміотерапії. За схемою DCF лікування отримували $13,1 \%$ хворих, ECF (епірубі- 
цин, цисплатин, флуороурацил) $-41,6 \%, \mathrm{CF}$ (цисплатин + 5-флуороурацил) - 37,8\%, FOLFOX - 11,8\%, FOLFIRI (лейковорин + 5-флуороурацил + іринотекан) $-6,5 \%$, за іншими схемами $-2,3 \%$. Загальна 3 -річна виживаність у групі DCF становила 73\%; у групах із використанням інших схем хіміотерапії $-55 \%$, однак різниця у виживаності виявилася статистично незначущою ( $\mathrm{p}=0,0961)$. Проте після подальшого аналізу було виявлено, що під час лікування за схемою DCF на $45 \%$ знижувався ризик рецидиву у порівнянні з іншими схемами (коефіцієнт небезпеки $=0,55,95 \%$ ДІ 0,27-1,13).

У дослідженні NCT01216644 показана беззаперечна перевага режиму FLOT (5-флуороурацил, лейковорин, оксаліплатин, доцетаксел) порівняно зі схемою ЕСF/ECX (епірубцин, цисплатин, 5-флуороурацил або капецитабін) у якості періопераційної хіміотерапії у пацієнтів з місцево-поширеним РШ (аденокарцинома) чи стравохідно-шлункового переходу [24]. Дослідниками було виявлено, що при використанні схеми FLOT спостерігалося статистично значуще покращення безрецидивної виживаності ( 30 проти 18 міс) $(\mathrm{p}=0,036)$ та загальної виживаності (50 проти 35 міс) $(\mathrm{p}=0,012)$.

\section{ВИСНОВКИ}

1. НАХПТ є опцією вибору при раку нижньої третини стравоходу та раку кардіоезофагеального переходу $(\mathrm{p}<0,05)$.

2. На сьогодні у масштабних рандомізованих дослідженнях АХПТ не продемонструвала перевагу перед АХТ у строках виживаності пацієнтів, проте АХПТ може бути призначена хворим, яким було виконано лімфодисекцію на рівні <D2 при R0, та у пацієнтів з R1-2 незалежно від рівня лімфаденектомії.

3. Ад’ювантна терапія S1 (пероральним фторпіримідином) демонструє високі показники загальної та безрецидивної виживаності у пацієнтів азіатського походження ( $\mathrm{p}=0,003$ та $\mathrm{p}<0,001$ відповідно);

4. Передопераційна хіміотерапія як режим лікування у хворих на місцево-поширений РШ достовірно підвищує загальну виживаність пацієнтів та ефективність лікування $(\mathrm{p}<0,05)$.

Конфлікт інтересів: відсутній.

\section{СПИСОК ВИКОРИСТАНОЇ ЛІТЕРАТУРИ}

1. Fedorenko, Z., Michailovich, Y., \& Goulak, L. (2019). Bulletin of national cancer registry of Ukraine № 20 "Cancer in Ukraine, 2017 2018». Incidence, mortality, activities of oncological service. Retrieved from http://www.ncru.inf.ua/publications/BULL 20/index e.htm

2. NCCN Clinical Practice Guidelines in Oncology Version 2.2019. Gastric Cancer Retrieved from https://www.nccn.org/professionals/physician_gls/pdf/gastric.pdf

3. Smyth, E., Verheij, M., Allum, W., Cunningham, D., Cervantes, A., \& Ar nold, D. (2016). Gastric cancer: ESMO Clinical Practice Guidelines for diagnosis treatment and follow-up. Annals of Oncology, 27(Suppl 5), 38-49. Retreived from: https://www.esmo org/Guidelines/Gastrointestinal-Cancers/Gastric-Cancer

4. Ychou, M., Boig, V., Pignon, J. P., Conroy, T., Bouché, O., Lebreton, G., ...Rougier, P. (2011). Perioperative chemotherapy compared with surgery alone for resectable gastroesophageal adenocarcinoma: an FNCLCC and FFCD multicenter phase III trial. Journal of Clinical Oncology, 29(13), 1715-1721. doi: 10.1200/JCO.2010.33.0597

5. Schuhmacher, C., Gretschel, S., Lordick, F., Reichardt, P., Hohenberger, W., Eisenberger, C. F., ...Schlag, P. (2010). Neoadjuvant chemotherapy compared with surgery alone for locally advanced cancer of the stomach and cardia: European Organisation for Research and Treatment of Cancer Randomized Trial 40954. Journal of Clinical Oncology, 28(35), 5210-5218. doi: 10.1200/JCO.2009.26.6114

6. Stahl, M., Walz, M. K., Riera-Knorrenschild, J., Stuschke, M., Sandermann, A. Bitzer, M., ...Budach, W. (2009). Phase III comparison of preoperative chemotherapy compared with chemoradiotherapy in patients with locally advanced adenocarcinoma of the esophagogastric junction. Journal of Clinical Oncology, 27(6), 851-856. doi: 10.1016/i.ejca.2017.04.027

7. van Hagen, P., Hulshof, M. C. C. M., van Lanschot, J. J. B., Steyerberg, E. W., van Berge Henegouwe, M. I., Wijnhoven, B. P., ... van der Gaast, A. (2012). Preoperative chemoradiotherapy for esophageal or junctional cancer. The New England Journal of Medicine, 366, 2074-2084. doi: 10.1056/NEJMoa1112088

8. Association J. G. C. (2010). Japanese gastric cancer treatment guidelines (ver. 3) Gastric Cancer, 14(2), 113-123. doi: 10.1007/s10120-011-0042-4

9. Sakuramoto, S., Sasako, M., Yamaguchi, T., Kinoshita, T., Fujii, M., Nashimoto, A., ...Yamamura, Y. (2007). Adjuvant chemotherapy for gastric cancer with s-1, an oral fluoropyrimidine. The New England Journal of Medicine, 357(18), 1810-1820. doi: 10.1056/NEJMoa072252

10. The GASTRIC (Global Advanced/Adjuvant Stomach Tumor Research International Collaboration) Group (2010). Benefit of adjuvant chemotherapy for resectable gastric cancer. JAMA, 303(17), 1729-1737. doi: 10.1001/jama.2010.534

11. Bajetta, E., Floriani, I., Di Bartolomeo, M., Labianca, R., Falcone, A. Di Costanzo, F., ... Marchet, A. (2014). Randomized trial on adjuvant treatment with folfiri followed by docetaxel and cisplatin versus 5 -fluorouracil and folinic acid for radically resected gastric cancer. Annals of Oncology, 25(7), 1373-1378 doi: 10.1093/annonc/mdu146

12. Kang, Y. K., Chang, H. M., Yook, J. H., Ryu, M. H., Park, I., Min, Y. J., ...Kim, B. S. (2013). Adjuvant chemotherapy for gastric cancer: a randomised phase 3 trial of mito- mycin-c plus either short-term doxifluridine or long-term doxifluridine plus cisplatin after curative d2 gastrectomy (amc0201). British Journal of Cancer, 108(6), 1245-1251. doi: $10.1038 /$ bjc. 2013.86

13. Yamada, S., Ritchim, P., Charkrabandhu, T., \& Jongraksat, W. (2012). Combination 5-fluoruracil/cisplatinum versus 5 -fluoruracil/leucovorin adjuvant chemotherapy efficacy for $\mathrm{r} 0$ gastric resection in locally invasive gastric cancer. Journal of the Medical Association of Thailand, 95(12), 1517-1523. Retrieved from https:// pdfs.semanticscholar.org/fa5d/05272bd65241b463844bf2ae57a81d07b59b.pdf

14. Jácome, A. A., Wohnrath, D. R., Scapulatempo Neto, C., Fregnani, J. H., Quinto, A. L., Oliveira, A. T., ...Santos, J. S. (2013). Effect of adjuvant chemoradiotherapy on overall survival of gastric cancer patients submitted to d2 lymphadenectomy. Gastric Cancer, 16(2), 233-238. doi: 10.1007/s10120-012-0171-4

15. Smalley, S. R., Benedetti, J. K., Haller, D. G., Hundahl, S. A., Estes, N. C., Ajani, J. A., ... Macdonald, J. S. (2012). Updated analysis of swog-directed intergroup study 0116: a phase iii trial of adjuvant radiochemotherapy versus observation after curative gastric cancer resection. Journal of Clinical Oncology, 30(19), 2327-2333. doi: $10.1200 / J C O .2011 .36 .7136$

16. Costa, W. L. Jr., Coimbra, F. J., Fogaroli, R. C., Ribeiro, H. S., Diniz, A. L., Begnami, M. D., ...Montagnini, A. L. (2012). Adjuvant chemoradiotherapy after d2lymphadenectomy for gastric cancer: the role of $n$-ratio in patient selection. results of a single cancer center. Radiation Oncology, 7, 169. doi: 10.1186/1748-717X-7-169

17. Park, S. H., Sohn, T. S., Lee, J., Lim, D. H., Hong, M. E., Kim, K. M. ...Kang, W. K. (2015). Phase III trial to compare adjuvant chemotherapy with capecitabine and cisplatin versus concurrent chemoradiotherapy in gastric cancer: final report of the adjuvant chemoradiotherapy in stomach tumors trial, including survival and subset analyses. Journal of Clinical Oncology, 33(28), 3130-3136. doi: 10.1200/JCO.2014.58.3930

18. Turanli, S., Atalay, C., Berberoglu, U., \& Gulben, K. (2015). Adjuvant chemoradiation versus chemotherapy for stage III gastric cancer after surgery with curative intent. Journal of Cancer Research and Therapeutics, 11(2), 369-374. doi: 10.4103/0973-1482.160050

9. Fazio, N., Biffi, R., Maibach, R., Hayoz, S., Thierstein, S., Brauchli, P. Roth, A. D. (2016). Preoperative versus postoperative docetaxel-cisplatin-fluorouracil (tcf) chemotherapy in locally advanced resectable gastric carcinoma: 10-year follow-up of the sakk 43/99 phase III trial. Annals of Oncology, 27(4), 668-673. doi: 10.1093/annonc/mdv620

20. Sun, Z., Zhu, R. J., Yang, G. F., \& Li, Y. (2014). Neoadjuvant chemotherapy with folfox 4 regimen to treat advanced gastric cancer improves survival without increasing adverse events: a retrospective cohort study from a chinese center. The Scientific World Journal, 2014(e418694) doi: 10.1155/2014/418694

21. Dikken, J. L., van Sandick, J. W., Maurits Swellengrebel, H. A., Lind, P. A., Putter, H., Jansen, E. P., ...Cats, A. (2011). Neoadjuvant chemotherapy followed by surgery and chemotherapy or by surgery and chemoradiotherapy for patients with resectable gastric cancer (critics). BMC Cancer, 11, 329. doi: 10.1186/1471-2407-11-329

22. Li, Z. Y., Koh, C. E., Bu, Z. D., Wu, A. W., Zhang, L. H., Wu, X. J., ...Ji, J. F. (2012). Neoadjuvant chemotherapy with folfox: improved outcomes in chinese patients with locally advanced gastric cancer. Journal of Surgical Oncology, 105(8), 793-799. doi: $10.1002 /$ jso.23009

23. Kim, S., Paget-Bailly, S., Messager, M., Nguyen, T., Mathieu, P., Lamfichekh, N., ...Borg, C. (2017). Perioperative docetaxel, cisplatin, and 5-fluorouracil compared to standard chemotherapy for resectable gastroesophageal adenocarcinoma. European Journal of Surgical Oncology, 43(1), 218-225. doi: 10.1016/j.ejso.2016.06.395

24. Al-Batran, S. E., Homann, N., Pauligk, C., Goetze, T. O., Meiler, J., Kasper, S., Hofheinz, R. D. (2019). Perioperative chemotherapy with fluorouracil plus leucovorin, oxaliplatin, and docetaxel versus fluorouracil or capecitabine plus cisplatin and epirubicin for locally advanced, resectable gastric or gastro-oesophageal junction adenocarcinoma (FLOT4): a randomised, phase 2/3 trial. Lancet, 393(10184), 1948-1957. doi: 10.1016/S0140-6736(18)32557-1

\section{Современные методы комплексного}

и персонифицированного лечения рака желудка (обзор литературы)

\section{А.П. Колесник, Е.Н. Левик, А.В. Каджоян, В.А. Кузьменко,}

\section{Д.Е. Чернявский}

Запорожский государственный медицинский университет

Резюме. На сегодня рак желудка является одной из наиболее актуальных проблем современной онкологии. Согласно данным Национального канцер-регистра, по показателям заболеваемости и смертности рак желудка занимает 4-е место $(7,1 \%)$ среди мужчин и 8 -е место $(4,2 \%)$ - среди женщин. По данным литературы, общая 5-летняя выживаемость при резектабельном раке желудка составляет около 53,5\%, поэтому проблема правильного выбора тактики лечения является чрезвычайно актуальной. Согласно международным рекомендациям в качестве терапии для больных с резектабельным раком желудка IB-III стадии применяются несколько вариантов комплексного лечения: неоаљювантная химиотерапия или неоадъювантная химиолучевая терапия с последующим хирургическим лечением; адъювантная химиотерапия или адъювантная химиолучевая терапия после хирургического вмешательства; предоперационная химиотерапия, состоящая из неоадъювантной и адъювантной химиотерапии. В данной статье проанализированы результаты клинических исследований, основной целью которых было установить наиболее эффективный подход к лечению рака желудка IB-III стадии путем сочетания различных методов терапии. Цель работы: обзор специализированной научной литературы для выяв- 


\section{Оглядові статті / Review Articles}

ления наиболее эффективного подхода к лечению больных раком желудка IB-III стадии.

Ключевые слова: рак желудка; клиническое исследование; комплексное лечение; хирургическое лечение; химиотерапия; химиолучевое лечение; выживаемость.

\section{Modern methods of complex and personalized treatment of stomach cancer (literature review)}

O.P. Kolesnik, O.M. Levyk, A.V. Kadzhoian, V.O. Kuzmenko,

D.Y. Cherniavskyi

Zaporizhzhia State Medical University

Summary. Today, stomach cancer is one of the most topical problems of modern oncology. According to the morbidity and mortality rates data of the National Cancer Register, gastric cancer takes $4^{\text {th }}$ place $(7.1 \%)$ among men and $8^{\text {th }}$ place $(4.2 \%)$ among women. According to the literature, the overall 5-year survival rate for resectable gastric cancer is approximately $53.5 \%$, so the problem of choosing the right treatment tactics is extremely relevant. According to international recommendations, several treatment options are used as therapy for patients with resectable gastric cancer of the IB-III stages: neoadjuvant chemotherapy or neoadjuvant chemotherapy + radiation therapy followed by surgical treatment; adjuvant chemotherapy or adjuvant chemotherapy + radiation therapy after surgery; perioperative chemotherapy consisting of neoadjuvant chemotherapy and adjuvant chemotherapy. This article analyzes the results of clinical trials, the main purpose of which was to establish the most effective approach to the treatment of gastric cancer of IB-III stages by combining various treatment methods. Purpose: a review of specialized scientific literature to identify the most effective approach for the treatment of patients with gastric cancer of IB-III stages.

Key words: gastric cancer; clinical trial; complex treatment; surgery; chemotherapy; chemoradiotherapy; survival.

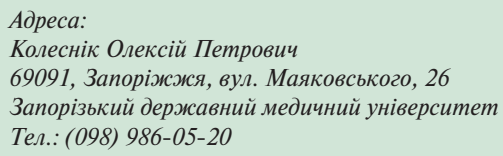

E-mail: oleksiikolesnik@gmail.com

E-mail: oleksiikolesnik@gmail.com 